Supplement of The Cryosphere, 13, 1877-1887, 2019

https://doi.org/10.5194/tc-13-1877-2019-supplement

(C) Author(s) 2019. This work is distributed under

the Creative Commons Attribution 4.0 License.

(c) (1)

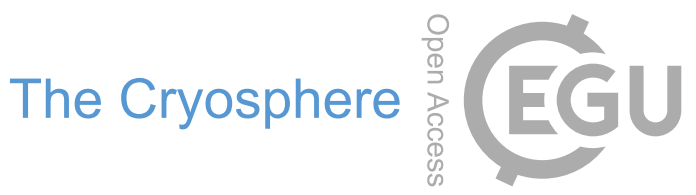

Supplement of

\title{
Buoyant forces promote tidewater glacier iceberg calving through large basal stress concentrations
}

Matt Trevers et al.

Correspondence to: Matt Trevers (matt.trevers@ bristol.ac.uk)

The copyright of individual parts of the supplement might differ from the CC BY 4.0 License. 
(a)

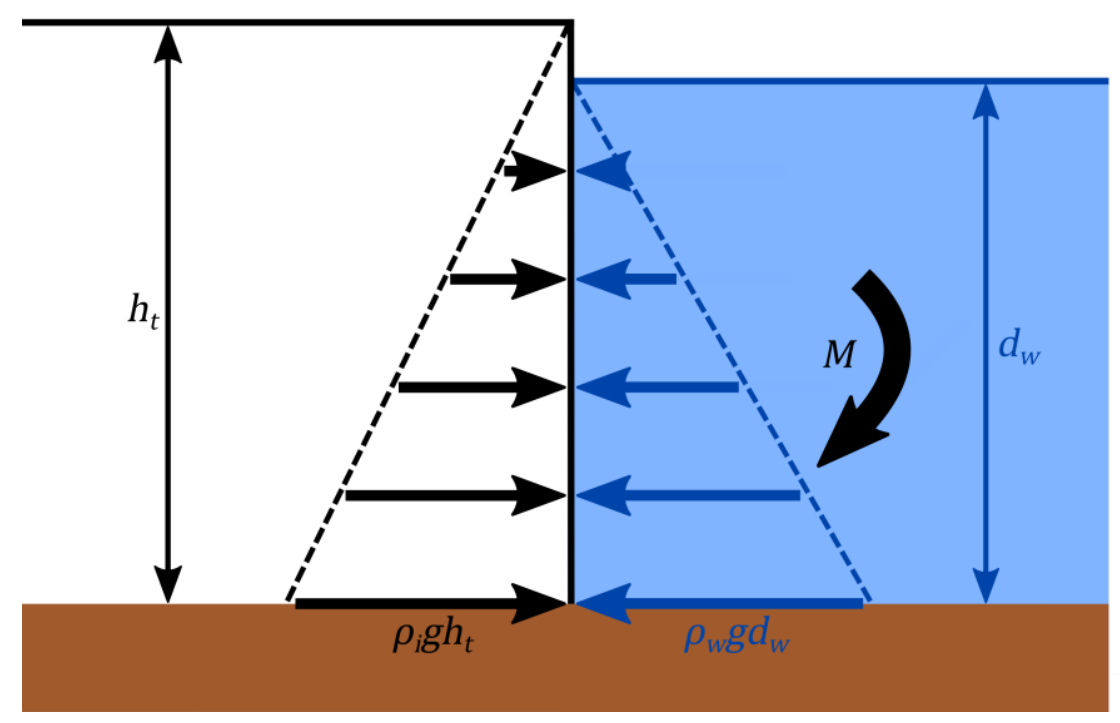

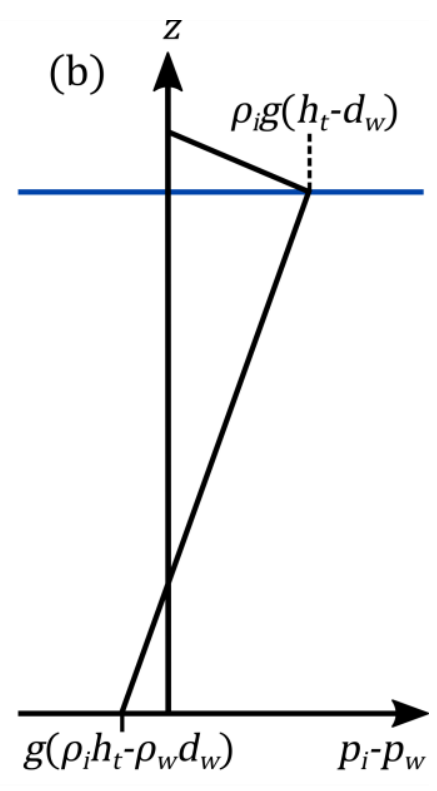

Figure S1. Pressure imbalance acting on the calving face, following Reeh (1968). (a) Schematic showing the horizontal cryostatic and hydrostatic stresses acting on the calving face. (b) Plot describing how the total horizontal stress varies across the calving face. Note that this plot assumes that the terminus thickness is less than the flotation thickness. $M$ is the bending moment. 


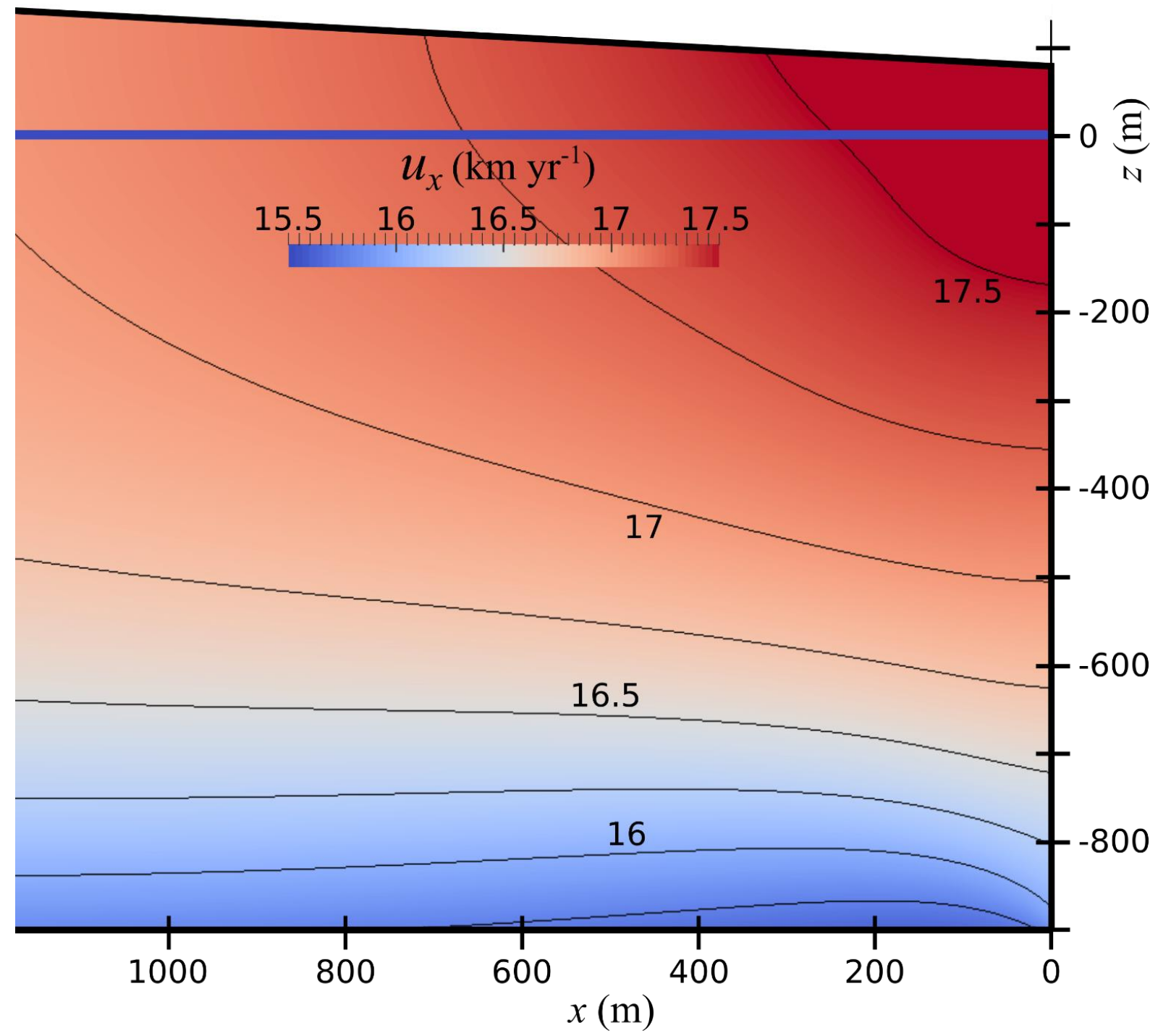

Figure S2. Longitudinal velocity map of the terminus of the glacier prior to the cutting of a notch, with contours at 0.25 $\mathrm{km} \mathrm{yr}^{-1}$ spacing. All simulation parameters are the same as in Fig. 3. 


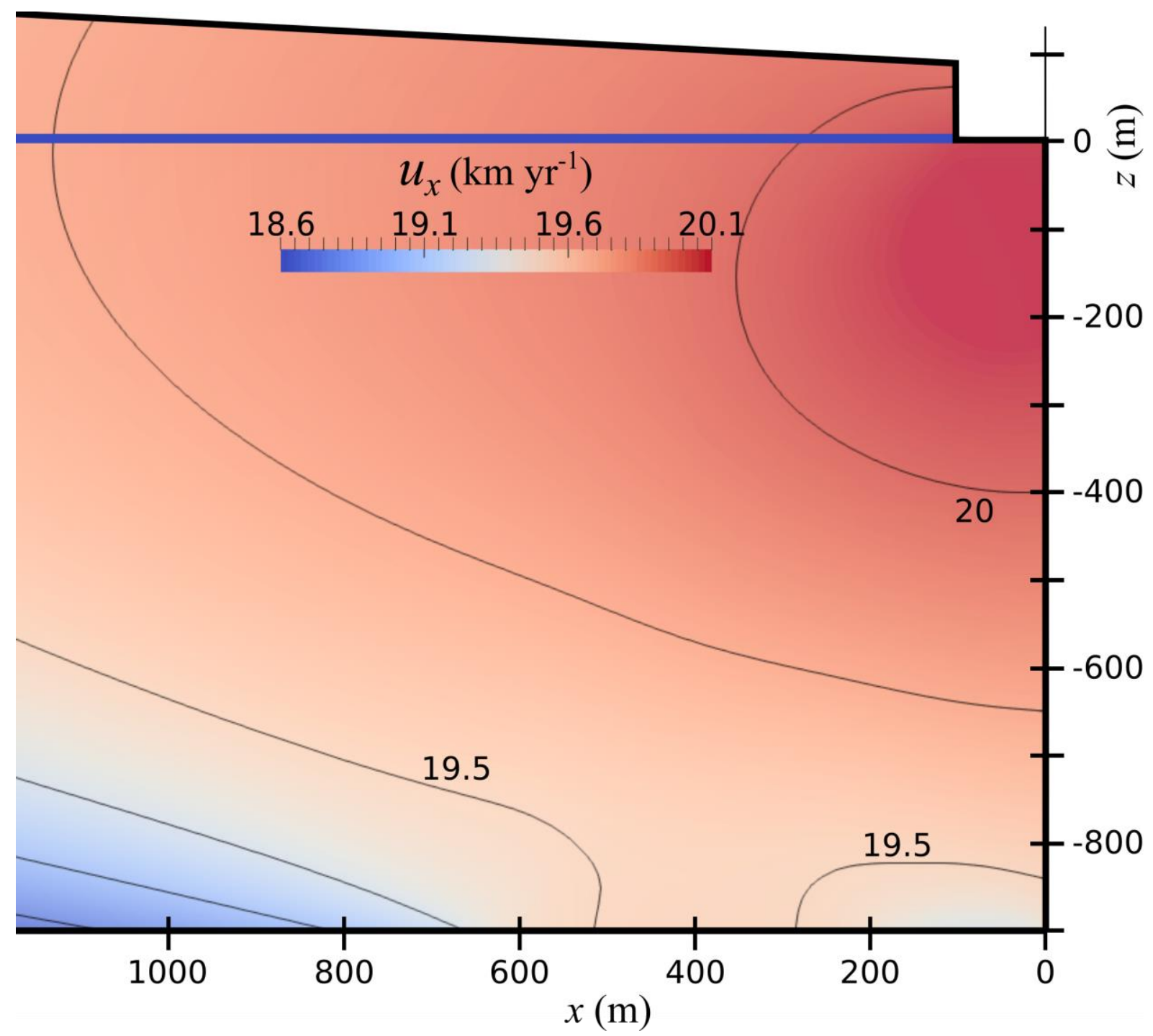

Figure S3. Longitudinal velocity map of the terminus of the glacier with a notch cut to a length $l_{n}=100 \mathrm{~m}$, with contours at $0.25 \mathrm{~km} \mathrm{yr}^{-1}$ spacing. All simulation parameters are the same as in Fig. 4. 